\title{
A cross-linked manganese porphyrin as highly efficient heterogeneous catalyst for selective oxidation of cycloalkenes/alkanes
}

\author{
MANOJ KUMAR SINGH and DEBKUMAR BANDYOPADHYAY* \\ Department of Chemistry, Indian Institute of Technology Delhi, Hauz Khas, New Delhi 110 016, India \\ e-mail:dkbp@chemistry.iitd.ac.in
}

MS received 4 February 2014; revised 30 April 2014; accepted 6 May 2014

\begin{abstract}
The monomeric tetrakis (5,10,15,20- $p$-bromophenyl) manganese porphyrin has been converted to a micro- and mesoporous material of surface area $1301 \mathrm{~m}^{2} / \mathrm{g}$ by carefully manipulating the reaction conditions of Suzuki coupling. This material has been tested for its oxidizing ability of cycloalkenes/alkane by $t$ - $\mathrm{BuOOH}, \mathrm{H}_{2} \mathrm{O}_{2}$, CumOOH and m-CPBA. The catalyst is found to oxidize the alkenes selectively and it is not destroyed even 5\% in 10 cycles of successive oxidation processes in one pot. The parent monomer gets destroyed appreciably under similar oxidizing conditions.
\end{abstract}

Keywords. Metalloporphyrin; suzuki coupling; heterogeneous catalysts; oxidation.

\section{Introduction}

The cytochrome P450 and its model compound catalyzed oxidation reactions have been extensively explored over several decades. ${ }^{1-5}$ In model compound studies, tetraphenyl M(III) porphyrins (TPPM(III), where $\mathrm{M}=\mathrm{Fe}, \mathrm{Mn}$ ) were found to mimic many reactions of the enzyme. ${ }^{6,7}$ These two metalloporphyrins, under different oxidizing conditions, have been very extensively investigated. In case of iron(III) and manganese(III) porphyrins, it has been well-established that the $\mu$-oxo-dimers were formed from the starting catalysts during the oxidation reactions (scheme 1) causing major damage to the main catalytic cycle. ${ }^{8,9}$

Many electronegatively substituted and sterically encumbered metalloporphyrins were employed to improve the survival of the catalyst. ${ }^{10-12}$ The stability of the catalyst was indeed improved. But in homogeneous catalytic systems, the separation of the catalysts from the reactants/products and also the higher cost of the halogenated catalysts were posing major problems for their industrial applications. It is to be noted that the native enzyme in biological systems is embedded in organs such as liver, etc. ${ }^{13}$ Thus the enzymatic destruction is minimal in the in vivo oxidation reactions. In order to avoid this, the encapsulation or attachment of functionalized metalloporphyrins on solid surfaces such as polyethylene glycol, ${ }^{14}$ double hydroxides, ${ }^{15}$ molecular squares ${ }^{16}$ and silica supports are done. ${ }^{17,18}$ The major

\footnotetext{
*For correspondence
}

problem in such materials is their limited surface area of actual catalytic sites and this has limited their systematic study for further developments. Recently some of the catalysts have been prepared by covalent approach. These materials are amorphous in nature due to the conjugated structures. However, limited studies on oxidation of thio ether compounds and a few cycloalkenes have been reported with such catalysts. ${ }^{19,20}$ Herein we report our synthetic approach on evolving a material of high surface area from a very common, low-cost porphyrin complex: $p$-tetra bromophenyl manganese (III) porphyrin chloride. The amorphous material, prepared by Suzuki coupling, has a surface area of $1301 \mathrm{~m}^{2} / \mathrm{g}$. Details of the method of the synthesis of this material and its catalytic property are reported here.

\section{Experimental}

\subsection{Materials}

Organic solvents were distilled over appropriate drying reagents under argon or obtained as dehydrated reagent from Merck's chemical. Deuterated solvents for NMR measurement, benzene 1,4 diboronic acid and caesium carbonate were obtained from Sigma-Aldrich. Pyrrole, $p$-bromobenzaldehyde, propionic acid and manganese (II) acetate tetrahydrate were also obtained from Merck's chemical while tetrakis (triphenylphosphine) palladium $(0)$ was obtained from spectrochemicals. Norbornene, cyclohexene, cyclohexane, cyclooctene and all the oxidation product standards, dodecane (internal 


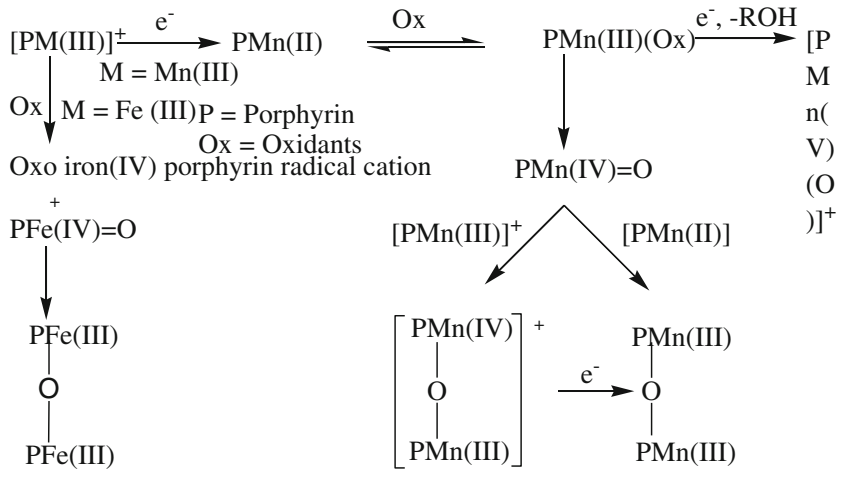

Scheme 1. Possible pathways of the destruction of metal centres of metalloporphyrins during their reaction with various oxidants.

standards) were purchased from Aldrich and were used as received without further purification. $t-\mathrm{BuOOH}$ $(\sim 70 \%)$ and $\mathrm{H}_{2} \mathrm{O}_{2}(\sim 30 \%)$ were purchased from Sigma-Aldrich as solution in water. CumOOH (Cumyl$\mathrm{OOH}$ ) was purchased from Fluka as $\sim 80 \%$ solution in cumene and m-chloroperbenzoic acid was recrystallized up to $97 \%$ purity. The exact active oxygen content of these oxidants was determined iodometrically prior to use. All the monmeric non-metallated and metalloporphyrins were synthesized according to literature procedure. ${ }^{21}$

\subsection{Catalyst preparation}

The synthesis of the proposed cross-linked manganese catalyst was conducted first by reacting a mixture of tetrakis $(5,10,15,20$ bromophenyl) porphyrin $\mathrm{Mn}(\mathrm{III})$ chloride ( $400 \mathrm{mg}, 0.39 \mathrm{mmol}$ ) and benzene 1,4 diboronic acid $(112 \mathrm{mg}, 0.67 \mathrm{mmol})$ in 1,4 dioxane $(25 \mathrm{~mL})$ under argon. To the mixture was added methanol $(5 \mathrm{~mL}), \mathrm{Cs}_{2} \mathrm{CO}_{3}(403 \mathrm{mg}, 1.24 \mathrm{mmol})$ and $\mathrm{Pd}\left(\mathrm{PPh}_{3}\right)_{4}(50 \mathrm{mg}, 43 \mu \mathrm{mol})$. The mixture was stirred at $110^{\circ} \mathrm{C}$ for $48 \mathrm{hrs}$. Finally, the mixture was allowed to cool at room temperature and was poured into water. The precipitate was collected by filtration and then thoroughly washed with water, THF, methanol and acetone after filtration. Then it was also rigorously washed by Soxhlet extraction for $24 \mathrm{hrs}$. with THF, methanol and acetone. It was dried in vacuum to give a material as dark green solid (300 mg) with $89 \%$ yield.

\subsection{Catalyst characterization}

Solid state ${ }^{1} \mathrm{H}_{-}{ }^{13} \mathrm{C}$ CP/MS NMR spectra were recorded by Bruker model 500MHz. Diffuse reflectance and UVVisible spectra were recorded by PerkinElmer UV-Vis spectrometer Lambda Bio 20 model and Agilent Technologies 8453 model respectively. Fourier transformed infrared spectra (FTIR) were recorded on $\mathrm{KBr}$ pellets using Agilent Technologies Cary 660 model. SEM images and EDX was recorded ZEISS EVO Series Microscope model EVO50. High-resolution electron microscopes (HR-TEM) images were recorded by PHILIPS Model CM 200. Metal concentration was measured by Inductively Coupled Plasma-Atomic Absorption Spectrometer (ICP-AAS) with Perkin Elmer instruments Analyst 100 model. Elemental analysis $(\mathrm{C}, \mathrm{H}, \mathrm{N})$ was measured by Perkin Elmer instrument series II CHNS/O Analyser 2400 model. Powder X-ray data were collected on a Bruker D8 Advance diffractometer using Ni-filtered $\mathrm{CuK} \alpha$ radiation. Data were collected with a step size of $0.02^{\circ}$ and a count time of $2 \mathrm{~s}$ per step over the range $2^{\circ}<2 \theta<70^{\circ}$. Nitrogen physisorption study was done with Quantachrome NovaWin-Data Acquisition and Reduction for NOVA instruments (C)1994-2007, Quantachrome Instruments version 10.01 at $77 \mathrm{~K}$. The samples were degassed up to $150^{\circ} \mathrm{C}$ for $12 \mathrm{~h}$.

\subsection{Oxidation of cycloalkenes/alkane}

The oxidations of cycloalkenes/alkane $(425 \mathrm{mM})$ were carried out at room temperature in a $4 \mathrm{~mL}$ screw-capped vial fitted with PTFE septa. In all the experiments the cross-linked manganese porphyrin catalyst $(2 \mathrm{mg})$ in $2.0 \mathrm{~mL}$ dichloromethane was used. The oxidation reactions were initiated by adding the oxidants $(10 \mathrm{mM})$ at the end to the vial. This was followed by stirring the reaction mixture with a small magnetic bar and the reactions were carried out either under argon or under oxygen depending upon the objective of study. After the reaction was over, $2 \mu \mathrm{L}$ dodecane was added to this reaction mixture as an internal standard and an aliquot $(\sim 1 \mu \mathrm{L})$ was withdrawn after regular intervals using a microlitre syringe from the reaction mixture for analysis. At the end of the reaction, the solid particles (catalyst) were separated by filtration and the product analysis for cycloalkenes/alkane oxidation was performed using Perkin-Elmer AutoSystemXL gas chromatography equipped with flame ionization detector (FID) and carbowax capillary column of $30 \mathrm{~m}$ length.

\section{Results and Discussion}

\subsection{Characterizations}

This polymeric catalyst was synthesized by SuzukiMiyaura cross-coupling polycondensation of a manganese(III) tetrakis(4-bromophenyl) porphyrin ([ $p$ $\mathrm{Br}]_{4} \mathrm{PMn}$ ) derivative and benzene 1,4 diboronic acid in thepresence of $\operatorname{Pd}(0)$ as catalyst under alkaline 
condition. Such polycondensation reaction leads to an inherent porous polymer with a built-in manganese(III) porphyrin framework. We examined the polycondensation reaction using solvent systems dioxane/methanol in alkaline $\mathrm{Cs}_{2} \mathrm{CO}_{3}$, with the aim of achieving large surface areas for the resulting polymers. As an optimal condition, polycondensation in dioxane/methanol (5/1 in vol.) in the presence of $\mathrm{Cs}_{2} \mathrm{CO}_{3}$ as base and $\mathrm{Pd}\left(\mathrm{PPh}_{3}\right)_{4}$ as catalyst allows for the preparation of manganese cross-linked polymer with large surface areas. After repeated rinse with water, THF, methanol and acetone, manganese cross-linked porphyrin was rigorously washed by soxhlet extraction for $24 \mathrm{hrs}$. with THF, methanol and acetone as solvents respectively, to remove any entrapped molecules and impurities, and then dried under vacuum overnight. Nitrogen sorption isotherm measurements of manganese cross-linked porphyrins at $77 \mathrm{~K}$ displayed a typical type-III sorption isotherm curve along with large adsorption at low pressure $\left(\mathrm{P} / \mathrm{P}_{0} \varangle 0.1\right)$, which is suggestive of the coexistence of micro- and mesopores in the framework. The Brunauer-Emmett-Teller (BET) surface areas were determined to be $1301 \mathrm{~m}^{2} / \mathrm{g}$ (figure S6). The average pore size were observed to be in the range of 2.2$2.4 \mathrm{~nm}$ (by non local-density functional theory) for catalyst which is very close to the size of a cube forming by four porphyrins unit $(\sim 2.4 \mathrm{~nm}) .{ }^{20 \mathrm{~b}}$ On the basis of these data the most probable structure of catalysts could be as shown in scheme 2 .

The cross-linked manganese(III) porphyrin is stable and insoluble in most of the organic solvents as expected as a result of a cross-linked network. Owing to the high-spin paramagnetic effect, the solid state ${ }^{1} \mathrm{H}-{ }^{13} \mathrm{C}$ CP/MS NMR spectrum of cross-linked manganese(III) porphyrin gave only a weak and broad peak. The cross-linked manganese(III) porphyrin displayed a broad peak at 127 and 132 ppm assignable to the phenylene linkages and signals at 119 and $148 \mathrm{ppm}$ owing to the porphyrin macrocycles (figure S1). Electronic absorption spectroscopy displayed absorption bands at $485 \mathrm{~nm}$ attributed to the soret band at 580, 625 and $690 \mathrm{~nm}$ representing the Q bands of manganese(III) porphyrin units, respectively (figure $\mathrm{S} 2$ ). In relation to this, the IR spectrum of cross-linked manganese(III) porphyrin exhibited the characteristic N-Mn vibration band at $1005 \mathrm{~cm}^{-1}$, which is close to that observed in the $[p-\mathrm{Br}]_{4} \mathrm{PMn}$. The characteristic new vibration band was observed at $3025 \mathrm{~cm}^{-1}$ for $\mathrm{C}-\mathrm{H}$ stretching frequency of the phenylene linkages between manganese(III) porphyrin units (figure S3). Elemental analysis revealed that the $\mathrm{C}, \mathrm{H}, \mathrm{N}$ are $69.59 \%, 4.61 \%$, $5.61 \%$ (theoretical formula for an infinite $2 D$ polymer $\left.\left\{\mathrm{C}_{56} \mathrm{H}_{32} \mathrm{ClMnN}_{4}\right\} \mathrm{C} 78.93 \%, \mathrm{H} 3.78 \%, \mathrm{~N} 6.57 \%\right)$. The amount of manganese $4.0 \mathrm{wt} \%$ present in the catalyst was estimated by ICP-AAS. Electron dispersion X-ray (EDX) spectroscopy measurement also confirmed the existence of $\mathrm{Mn}, \mathrm{Cl}$, and $\mathrm{Br}$ (figure S5). These results indicate that manganese(III) porphyrin units were covalently integrated into porous framework of cross-linked manganese porphyrin.

The morphology and crystallinity of cross-linked manganese(III) porphyrin were investigated by scanning electron microscopy (SEM), transmittance electron microscopy (TEM) and powder X-ray diffraction (PXRD) measurements. SEM images displayed that cross-linked manganese(III) porphyrin adopts plateshaped monoliths of several micrometers in size for cross-linked manganese porphyrin (figure S4a). A

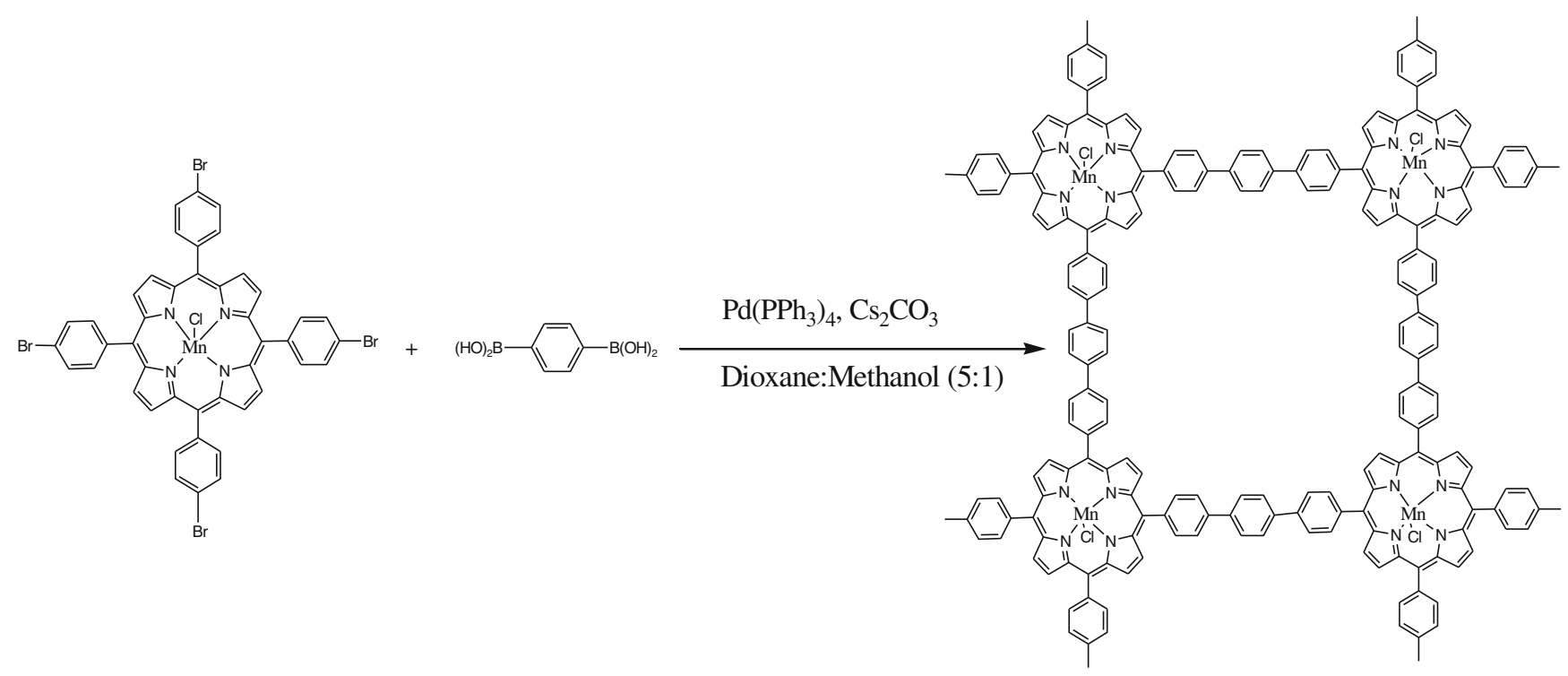

Scheme 2. Schematic representation of the synthesis of cross-linked manganese porphyrin. 


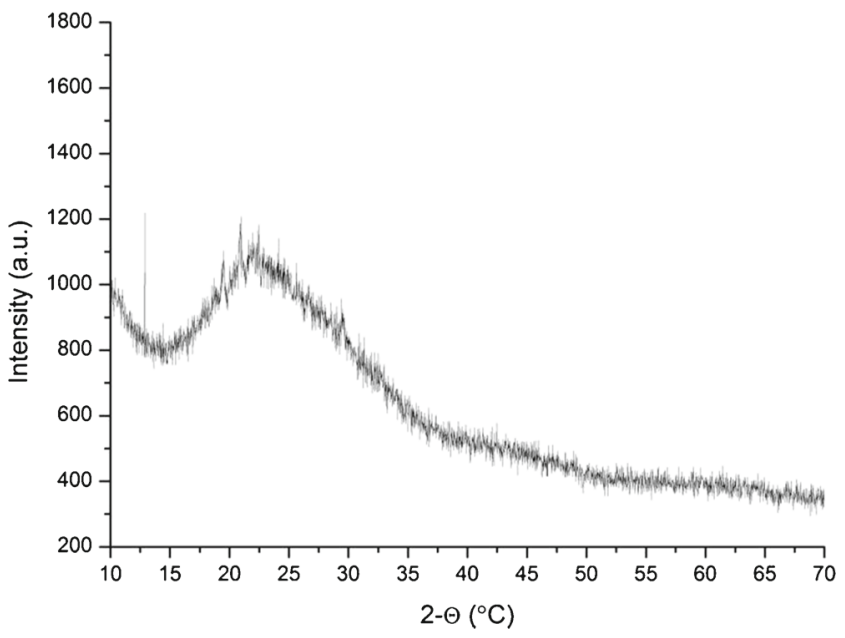

Figure 1. Powder X-ray diffraction pattern for cross-linked manganese(III) porphyrin.

closer look at high magnification SEM images showed that the monoliths consist of $\sim 100-300 \mathrm{~nm}$ sized elementary platelets, while their surfaces are quite rough. High resolution TEM images revealed the presence of nanometer-scale cavities (figure S4b). The PXRD profile confirmed the amorphous character of cross-linked manganese porphyrin (figure 1). Therefore, cross-linked manganese(III) porphyrin is an amorphous, insoluble and nanoporpous polymer bearing covalently linked manganese(III) porphyrin functionalities in the skeleton.

\subsection{Norbornene oxidation}

The catalytic behaviour of this catalyst was studied next. In this study we have judiciously chosen cis-2,3 norbornene as the alkene to be oxidized first because it is more difficult to oxidize with respect to other alkenes such as cyclohexene, etc., and secondly it gives many oxidation products. So, whether the catalyst has the property of selective oxidation is also answerable with this substrate. The oxidation of cis2,3 norbornene in the presence of this catalyst was thus conducted in dichloromethane by hydroperoxides and m-chloroperbenzoic acid under argon atmosphere.

It was observed that with monomeric manganese(III) porphyrin as catalysts; the $t$ - $\mathrm{BuOOH}, \mathrm{H}_{2} \mathrm{O}_{2}, \mathrm{CumOOH}$ and $\mathrm{m}$-CPBA oxidizes cis-2,3 norbornene to exo-2,3 epoxy norbornane with only $10 \%, 5 \%, 22 \%$ and $8 \%$ yields respectively with substantial destruction of catalysts. On the other hand, the corresponding yields were improved to $98 \%, 32 \%, 94 \%$ and $78 \%$ respectively using the cross-linked manganese(III) porphyrin as the catalyst. In the reactions it has been noted that the $\mathrm{CumOOH}$ reacts faster with respect to $t-\mathrm{BuOOH}$, and the conversion reached a maximum of $32 \%$ and $78 \%$ in case of $\mathrm{H}_{2} \mathrm{O}_{2}$ and m-CPBA (table 1).

Thus the selective oxidation of cis-2,3 norbornene to exo-2,3 epoxy norbornane by $t$ - $\mathrm{BuOOH}$ in $99 \%$

Table 1. Selective oxidation of norbornene by different oxidants.

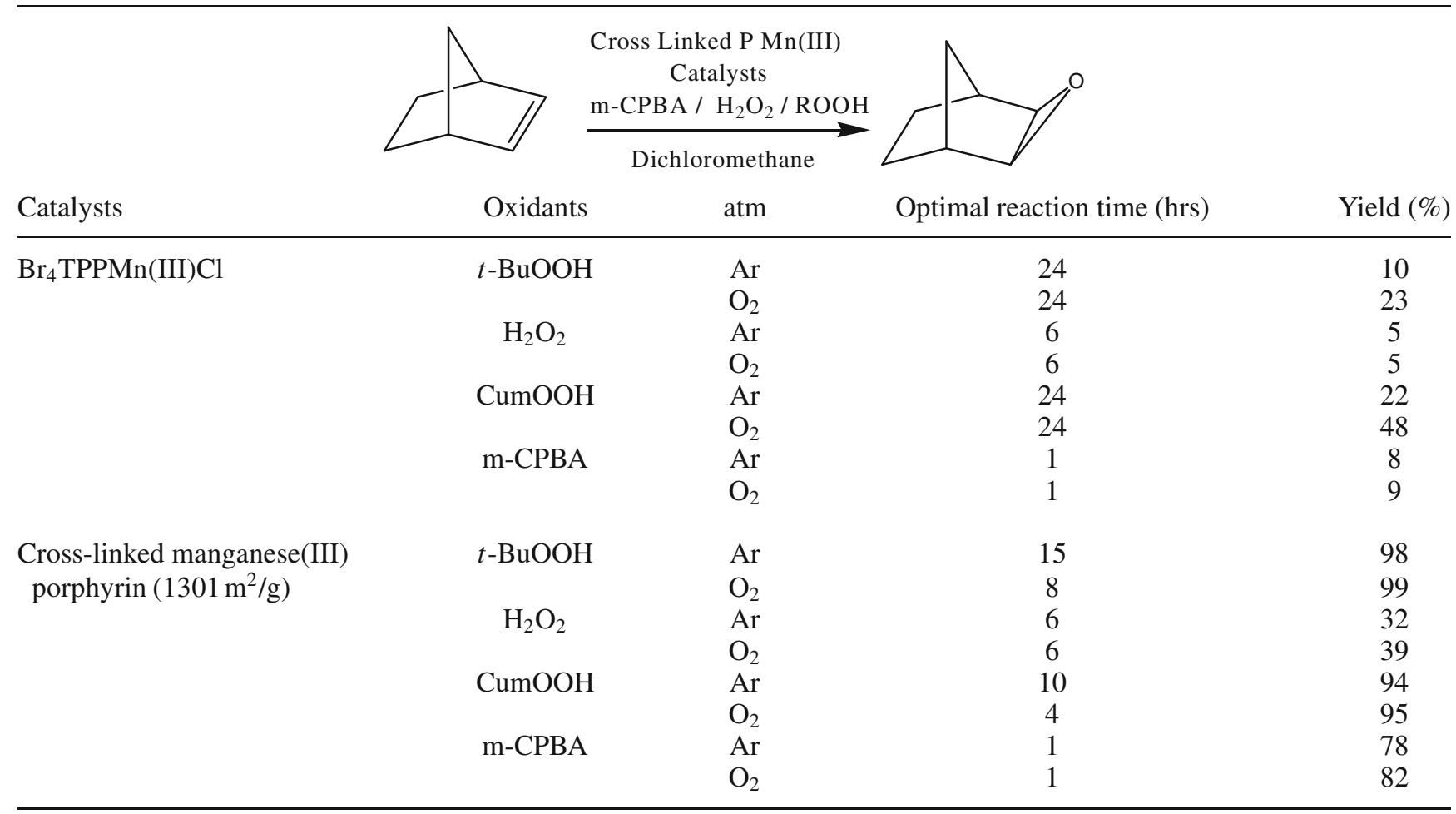

Norbornene $(425 \mathrm{mM})$, Oxidants $(10 \mathrm{mM})$, Catalysts $(2 \mathrm{mg})$, Dichloromethane $(2 \mathrm{~mL})$, stirred at room temperature under argon and oxygen atmosphere, conversion (\%) by GC. The yields are w.r.t. oxidants. 


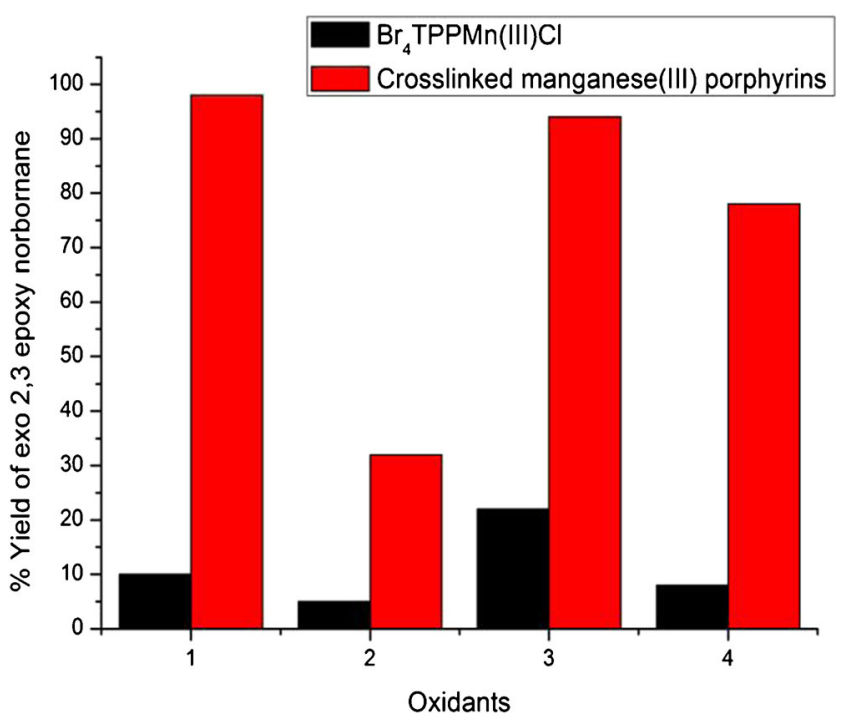

Figure 2. Norbornene was oxidized by various oxidants (1) $t$ - $\mathrm{BuOOH}$ (2) $\mathrm{H}_{2} \mathrm{O}_{2}$ (3) $\mathrm{CumOOH}$ (4) m-CPBA with catalysts $\mathrm{Br}_{4} \mathrm{TPPMn}(\mathrm{III}) \mathrm{Cl}$ and cross-linked manganese(III) porphyrin under argon atmosphere.

yields by using this cross-linked manganese(III) porphyrin has indeed been achieved. Notable was that the reaction time was much less in this case. It has also been observed that it behaves as a robust catalyst with no sign of any destruction for 10 such catalytic cycles studied by adding oxidants in aliquots after completion of each cycles. It was also observed that the conversion of cis-2,3 norbornene to exo-2,3 epoxy norbornane by $\mathrm{H}_{2} \mathrm{O}_{2}$ and m-CPBA were substantially increased from $10-32 \%$ and $35-78 \%$ respectively by changing the catalyst from monomer to cross-linked manganese(III) porphyrin (figure 2).
In these reactions it has been observed that the epoxidation of cis 2,3-norbornene was very high under oxygen atmosphere as compared to that in argon atmosphere for $t$ - $\mathrm{BuOOH}$ and $\mathrm{CumOOH}$. While in case of $\mathrm{H}_{2} \mathrm{O}_{2}$ and m-CPBA there was not much significant change under oxygen w.r.t. argon atmosphere (table 1, figure S7). The most rational way to understand the product profile under dioxygen would be through a radical path for hydroperoxides where the evolved $\mathrm{RO}^{\bullet}$ further reacts with dioxygen and generates $\mathrm{ROO}^{\bullet}$ radical and the increased yield of the product could be accountable due to this. ${ }^{14,22}$ Thus we believe the selective epoxidation of cis 2,3 norbornene by hydroperxides proceeds through radical path and the oxidation by m-CPBA through non-radical path.

\subsection{Oxidation of cyclohexene}

Next the catalytic oxidation reaction of cyclohexene by these hydroperoxides, hydrogen peroxide and m-CPBA were conducted. In these reactions it has been observed that cyclohexane epoxide, cyclohexenone and cyclohexenol were formed but cyclohexenone was stereoselectively found with $52-76 \%$ by various oxidants with monomer and cross-linked manganese(III) porphyrin. The catalytic behaviours of these catalysts are shown in table 2 .

\subsection{Oxidation of cyclooctene}

In the oxidation of this substrate it was observed that cyclooctane epoxide was formed selectively from cyclooctene oxidation by various oxidants with cross-

Table 2. The oxidation of cyclohexene.

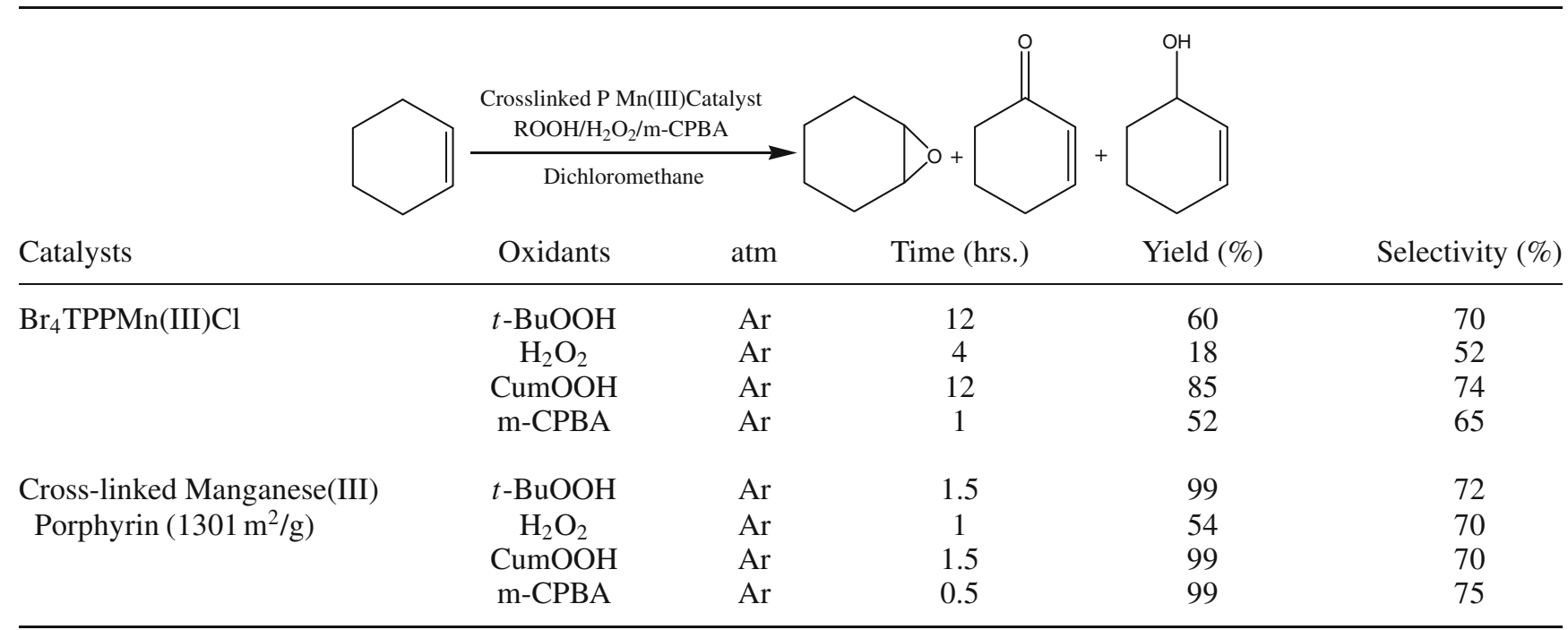

Cyclohexene (425 mM), Oxidants $(10 \mathrm{mM})$, Catalyst $(2 \mathrm{mg})$, Dichloromethane $(2 \mathrm{~mL})$, stirred at room temperature under argon and oxygen atmosphere, conversion (\%) by GC. The yields are w.r.t. oxidants. 
linked manganese(III) porphyrin. The comparative oxidation of cyclooctene with the monomeric catalyst is shown in table 3. In case of all the oxidants it has been noted that the cross-linked manganese polymeric catalyst is superior to the monomer.

\subsection{Oxidation of cyclohexane}

As usual it has been observed that it is very difficult to oxidize this alkane. Cyclohexane was oxidized by these hydroperoxides, $\mathrm{H}_{2} \mathrm{O}_{2}$ and m-CPBA into cyclohexanone (55-60\% stereoselectively) and cyclohexanol. The catalytic activity of these cross-linked manganese porphyrin was shown in table 4 by various oxidants. It was noted that cyclohexane was oxidized to cyclohexanone and cyclohexanol up to $29 \%$, with this polymeric catalyst by $\mathrm{CumOOH}$.

\subsection{Recyclability}

In these oxidizing systems it has been noted that the cross-linked manganese porphyrin was not destroyed after 10 cycles of the oxidation cycles. After completion of the first cycle to the same pot, another aliquate of oxidants were added and the yields of products in the mixture were measured in these processes and continuous oxidation has been noted till 10 cycles measured. This shows that this catalyst was more recyclable, robust and

Table 3. Selective oxidation of cyclooctene.

\begin{tabular}{|c|c|c|c|c|}
\hline Catalysts & $\begin{array}{l}\begin{array}{l}\text { Crosslink } \\
\text { ROOH/H }\end{array} \\
\text { Dic }\end{array}$ & $\rightarrow$ & Time (hrs.) & Yield (\%) \\
\hline $\mathrm{Br}_{4} \mathrm{TPPMn}(\mathrm{III}) \mathrm{Cl}$ & $\begin{array}{c}t-\mathrm{BuOOH} \\
\mathrm{H}_{2} \mathrm{O}_{2} \\
\mathrm{CumOOH} \\
\mathrm{m}-\mathrm{CPBA}\end{array}$ & $\begin{array}{l}\mathrm{Ar} \\
\mathrm{Ar} \\
\mathrm{Ar} \\
\mathrm{Ar}\end{array}$ & $\begin{array}{c}24 \\
6 \\
24 \\
1\end{array}$ & $\begin{array}{c}10 \\
5 \\
21 \\
10\end{array}$ \\
\hline $\begin{array}{l}\text { Cross-linked Manganese(III) } \\
\text { porphyrin }\left(1301 \mathrm{~m}^{2} / \mathrm{g}\right)\end{array}$ & $\begin{array}{c}t-\mathrm{BuOOH} \\
\mathrm{H}_{2} \mathrm{O}_{2} \\
\mathrm{CumOOH} \\
\mathrm{m}-\mathrm{CPBA}\end{array}$ & $\begin{array}{l}\mathrm{Ar} \\
\mathrm{Ar} \\
\mathrm{Ar} \\
\mathrm{Ar}\end{array}$ & $\begin{array}{c}18 \\
1.5 \\
8 \\
0.5\end{array}$ & $\begin{array}{l}91 \\
16 \\
99 \\
38\end{array}$ \\
\hline
\end{tabular}

Cyclooctene $(425 \mathrm{mM})$, Oxidants $(10 \mathrm{mM})$, Catalyst $(2 \mathrm{mg})$, Dichloromethane $(2 \mathrm{~mL})$, stirred at room temperature under argon and oxygen atmosphere, conversion (\%) by GC. The yields are w.r.t. oxidants.

Table 4. Selective oxidation of cyclohexane.

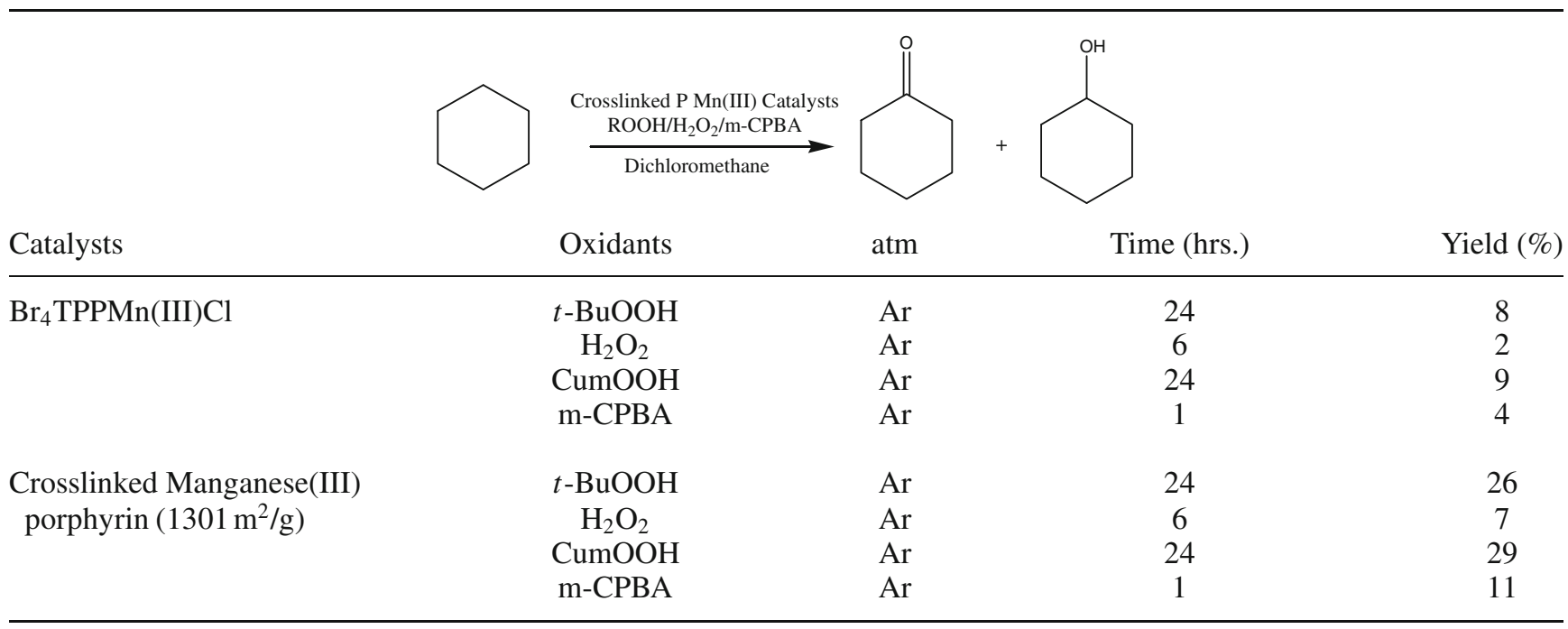

Cyclohexane $(425 \mathrm{mM})$, Oxidants $(10 \mathrm{mM})$, Catalyst $(2 \mathrm{mg})$, Dichloromethane $(2 \mathrm{~mL})$, stirred at room temperature under argon and oxygen atmosphere, conversion (\%) by GC. The yields are w.r.t. oxidants. 
enantioselective as compared to monomeric manganese porphyrin. The recyclability of cross-linked manganese porphyrin was shown in table S1 under argon and oxygen both.

\section{Conclusions}

The most easily degradable catalyst known, TPPMnCl has now been made to be a non-degradable catalyst, so that the representative catalyst does not require any electronegative substituent on porphyrin backbone. The catalyst with surface area of $1301 \mathrm{~m}^{2} / \mathrm{g}$ in particular was thus found to oxidize at least $1 / 4^{\text {th }}$ of the alkene present in the reaction flask selectively to the epoxide in one pot without much catalyst destruction. This result is very promising for the possible industrial application of the catalyst. The work on application of the catalytic oxidation of several other alkenes with this catalyst and the development of other similar catalysts are in progress.

\section{Supplementary Information}

Solid state ${ }^{1} \mathrm{H}-{ }^{13} \mathrm{C} C \mathrm{CP} / \mathrm{MS}$ NMR, electronic absorption spectroscopy, FTIR, SEM, HRTEM, EDX, N 2 physisorption isotherm, recyclability table, catalytic graph data.

\section{Acknowledgements}

We thank the Department of Science and Technology (DST), Government of India (Project no. SR/S1/IC-48/ 2010) for funding and UGC for the fellowship to MKS.

\section{References}

1. McMurry T J and Groves J T 1986 In Cytochrome P450: Structure, Mechanism and Biochemistry P R Ortiz de Montellano (ed.) (New York: Plenum Press) 1st edn. p1

2. Dolphin D, Traylor T G and Xie L Y 1997 Acc. Chem. Res. 30251

3. (a) Chang C J, Loh Z H, Shi C, Anson F C and Nocera D G 2004 J. Am. Chem. Soc. 126 10013; (b) Faure S, Stern C, Gguilard R and Harvey P D 2004 J. Am. Chem. Soc.126 1253; (c) Zhang Y, Yang R, Liu F and Li K A
2004 Anal. Chem. 76 7336; (d) Stephenson N A and Bell A T 2005 J. Am. Chem. Soc. 127 8635; (e) Agarwala A and Bandyopadhyay D 2006 Chem. Commun. 4823

4. (a) Aratani N, Kim D and Osuka A 2009 Acc. Chem. Res. 42 1922; (b) Bell S R and Groves J T 2009 J. Am. Chem. Soc. 1319640

5. Kumar D, Karamzadeh B, Sastry G N and de Visser S P 2010 J. Am. Chem. Soc. 1327656

6. (a) Gopalaiah K 2013 Chem. Rev. 113 3248; (b) Saha B, Gupta D, Abu-Omar M M, Modak A and Bhaumik A 2013 J. Catal. 299316

7. Shaik S, Lai W, Chen H and Wang Y 2010 Acc. Chem. Res. 431154

8. Boer D D, Li M, Habets T, Iavicoli P, Rowan A E, Nolte R J M, Speller S, Amabilino D B, Feyter S D and Elemans J A AW 2013 Nat. Chem. 5621

9. (a) Feiters M C, Rowan A E and Nolte R J M 2000 Chem. Soc. Rev. 29 375; (b) Hulsken B, Hameren R V, Gerritsen J W, Khoury T, Thordarson P, Crossley M J, Rowan A E, Nolte R J M, Elemans J A A W and Speller S 2007 Nat. Nanotechnol. 2285

10. Traylor T G, Tsuchiya S, Byun Y -S and Kim C 1993 J. Am. Chem. Soc. 1152775

11. Battioni P, Bartoli J F, Mansuy D, Byun Y S and Traylor T G 1992 J. Am. Chem. Soc. 1141051

12. He G-X and Bruice T C 1991 J. Am. Chem. Soc. 113 2747

13. Baylon J L, Lenov I L, Sligar S G and Tajkhorshid E 2013 J. Am. Chem. Soc. 1358542

14. Zhang J L, Huang J S and Che C M 2006 Chem. Eur. J. 123020

15. Halma M, Castro K A D de Freitas, Taviot-Gueho C, Prévot V Forano C, Wypych F and Nakagaki S 2008 J. Catal. 257233

16. Oxford G A E, Arana M C C, Majumder D, Gurney R W, Merlau M L, Nguyen S B T, Snurr R Q and Broadbelt L J 2009 J. Catal. 266145

17. Christoforidis K C, Louloudi M, Milaeva E R and Deligiannakis Y 2010 J. Catal. 270153

18. Erkisson K, Gothelid E, Puglia C, Backvall J E and Oscarsson S 2013 J. Catal. $\mathbf{3 0 3} 16$

19. (a) Suslick K S, Bhyrappa P, Chou J -H, Kosal M E, Nakagaki S, Smithenry D W and Wilson S R 2005 Acc. Chem. Res. 38 283; (b) Shultz A M, Farha O K, Hupp J T and Nguyen S T 2011 Chem. Sci. 2686

20. (a) Chen L, Yang Y and Jiang D $2010 \mathrm{~J}$. Am. Chem. Soc. 132 9138; (b) Chen L, Yang Y, Guo Z and Jiang D 2011 Adv. Mater. 23 3149; (c) Yang X L, Xie M H, Zou C, He Y, Chen B, O'Keeffe M and Wu C D 2012 J. Am. Chem. Soc. 13410638

21. Alder A D, Longo F R, Kampas F and Kim J $1970 \mathrm{~J}$. Inorg. Nucl. Chem. 322443

22. Zou C, Zhang Z, Xu X, Gong Q, Li J and De Wu C 2012 J. Am. Chem. Soc. 1348 